See discussions, stats, and author profiles for this publication at: https://www.researchgate.net/publication/332344820

\title{
The motivations that define eating patterns in some Mediterranean countries
}

Article in Nutrition \& Food Science · April 2019

DOI: 10.1108/NFS-12-2018-0360

CITATION

1

10 authors, including:

Raquel Pinho Ferreira Guiné

Polytechnic Institute of Viseu

472 PUBLICATIONS 1,998 CITATIONS

SEE PROFILE

Paula R. Correia

Polytechnic Institute of Viseu

84 PUBLICATIONS 724 CITATIONS

SEE PROFILE

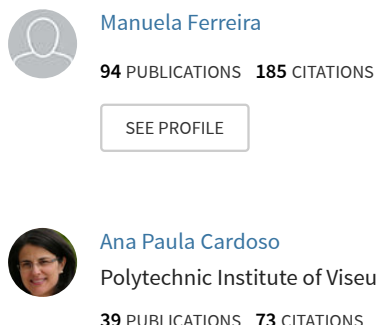

39 PUBLICATIONS 73 CITATIONS

SEE PROFILE

Some of the authors of this publication are also working on these related projects:

Bridges between family and organic farming View project

Guest editor, 'Foods' [MDPI], New insights into Cereals and Cereal-Based Foods View project 
Published article citation:

Author version Guiné RPF, Ferrão AC, Ferreira M, Correia P, Cardoso AP, Duarte J, Rumbak I, Shehata A-M, Vittadini E, Papageorgiou M. (2019) The motivations that define eating patterns in some Mediterranean countries. Nutrition and Food Science, 49(6), 1126-1141.

THE MOTIVATIONS THAT DEFINE EATING PATTERNS IN SOME MEDITERRANEAN COUNTRIES

6

Raquel P. F. Guiné ${ }^{1 *}$, Ana Cristina Ferrão ${ }^{1}$, Manuela Ferreira ${ }^{1}$, Paula Correia ${ }^{1}$, Ana Paula Cardoso', João Duarte', Ivana Rumbak², Abdel-Moneim Shehata ${ }^{3}$, Elena Vittadini ${ }^{4}$, Maria Papageorgiou ${ }^{5}$ Menoufia, Egypt ${ }^{4}$ Department of Food Science, University of Parma, Italy Technology, Thessaloniki, Greece

"Corresponding author:

20 Raquel P. F. Guiné

21 Escola Superior Agrária de Viseu, Quinta da Alagoa, Estrada de Nelas, Ranhados, 3500-606

22 Viseu, Portugal.

23 Tel: + 351232446 640; Fax: +351232426536

24 E-mail: raquelguine@esav.ipv.pt 
Abstract

29 Purpose: This study is part of the international project EATMOT, designed to investigate several issues related to food choice and consumption patterns in different countries,

31 including health related factors; economic and availability aspects; emotional

32 determinants; social, cultural and religious influences; marketing and advertising

33 campaigns and finally environmental concerns.

34 Methodology: The present study was based on a questionnaire that was exclusively prepared for the project, and which was applied to collect data in different countries, in particular Croatia, Egypt, Italy, Greece and Portugal, which are typically associated with the Mediterranean diet.

38 Findings: The results obtained allowed, in general, to conclude that in all 5 countries the motivations related to health as well as environment \& politics were the more relevant to

40 determine people's eating habits (scores varying from 0.3 to 0.7 ). Women were more influenced by eating motivations than men, and people with moderate exercise were more susceptible to health and environmental motivations and less to emotional, social or 43 marketing motivations ( $\mathrm{p}<0.001$ in all cases). It was also observed that people who 44 adopted a special diet were more prone to eating motivations and that the emotional 45 motivations were more pronounced in people with eating disorders ( $p<0.001)$. Finally, people without chronic diseases or allergies were even more influenced by health

47 motivations than those who actually suffered from these health problems $(\mathrm{p}<0.001$ in 48 both cases).

49 Originality/Value: This work is important due to the multinational coverage, thus

50 allowing to evaluate the most relevant factors that influenced the food choices of the 51 populations around the Mediterranean Sea, sharing the common link to the Mediterranean 
52 Diet. The study allowed concluding that, in general, the food choices were primarily

53 determined by health factors, and also by concerns related to the environment and 54 sustainability as well as by political influences.

56 Keywords: psychology of eating, questionnaire survey, healthy diet, traditional food

\section{INTRODUCTION}

The Mediterranean Diet (MD) is a dietary pattern usually followed by the people of some countries situated near to the Mediterranean Sea (Boccardi et al., 2018) and is characterized by a high consumption of vegetables, fruits, whole grains, legumes, nuts, and seeds; by an abundant consumption of olive oil, the privileged source of dietary fat; by a moderate to low consumption of animal products; and by a regular but moderate consumption of red wine at mealtimes (Ostan et al., 2015; Thodis et al., 2018; Trichopoulou et al., 2003). This dietary pattern is also associated with the importance of people eating with company, among family and friends (Boccardi et al., 2018). Moreover, the Mediterranean dietary patterns may vary according to age, gender, ethnicity, culture and other lifestyle factors (Barrea et al., 2018; Park et al., 2005). Scientific evidence has

69 shown that the adherence to the MD is associated with several health benefits, such as, 70 for example, a lower incidence of cancer, cognitive diseases and cardiovascular diseases (CVD) (Grosso et al., 2014; Renzella et al., 2018; Schwingshackl and Hoffmann, 2015; Singh, 2016). However, despite the benefits of this dietary pattern, some people are 73 changing the traditional MD by introducing unhealthier foods, such as low nutrient dense 74 foods (Castro-Quezada et al., 2014). In fact, choosing to adopt a specific dietary regimen involves different factors interrelated with each other (Köster, 2009; Organ et al., 2015). 
A healthy diet helps to protect against malnutrition in all forms, as well as noncommunicable diseases (NCDs), such as diabetes, heart disease, stroke and cancer (World Health Organization, 2018a). Nowadays, people are more aware about the association between the quality of the diet and their personal health (van Buul et al., 2017). However, despite this knowledge, even health-conscious consumers often make unhealthy food choices, because the knowledge about a healthy eating not always translates into a dietary change or into better eating habits (Mai and Hoffmann, 2014). During a day, individuals are confronted with several food choices, which are driven by reasons that they are not fully aware. Food choice is a complex system influenced by multiple factors related to the product (such as sensory properties), and also to the consumer (like for example restrictions or preferences) as well as the consumption context (culture, religion, health, convenience and price, biology, emotions, marketing, political and also environmental concerns) (Kaya, 2016; Pelly et al., 2018; Stasi et al., 2018). Among the different motivations that influence food choices, culture is one of the most important and explains the differences in food preferences across countries and cultures (Rozin, 2007; Siegrist et al., 2015). In fact, food consumption is closely related to the social context, since food, through its symbolic value, can help to successfully reveal people's identities and demonstrate who they are and where they belong within society (Barauskaite et al., 2018; Landström et al., 2009). Hence, given the urgency to improve people's eating habits (Leng et al., 2017), it is crucial to understand their food motivations, so that the policy recommendations can be more effective.

97 The project EATMOT with title "Psycho-social motivations associated with food choices and eating practices" aims to study the different psychological and social motivations that determine people's eating patterns in relation to their choices or eating

100 habits and the range of the study is multinational. In the frame of the project it was 
101 developed a questionnaire that compiled different perspectives provided by existing

102 research about the motivations on eating behaviour, but also extended them by including

103 other motives identified by the project team members.

104 This particular study intended to characterize the motivations that could define eating

105 patterns in the Mediterranean region, more specifically in 5 Mediterranean countries

106 (Croatia, Egypt, Italy, Greece or Portugal), which are typically associated with the

107 Mediterranean diet, and that define a region with characteristic food habits. The factors

108 investigated include aspects related to health, emotions, budget, availability, society,

109 culture, environment, politics, marketing and commerce. These allowed to characterize

110 the food choice determinants of the populations of the targeted region: countries

111 distributed around the Mediterranean Sea under the influence of the Mediterranean Diet,

112 recognized by UNESCO as a cultural heritage of humanity.

\section{2. DESCRIPTION OF OBSERVATIONAL STUDY}

\section{2.1. Questionnaire used for assessment of eating motivations}

116 For the EATMOT project a questionnaire was developed to investigate the psycho-

117 social motivations that influence food choices and eating habits. The questionnaire was

118 first prepared in English and then translated into the native languages of the participating

119 countries, following a double sided translation-checking methodology. The questionnaire

120 was structured in ten different parts: Part I - Sociodemographical data; Part II -

121 Anthropometric data and behavioural and health related elements; Part III - Attitudes

122 relating to healthy food; Part IV - Sources of information about a healthy diet; Part V -

123 Healthy motivations; Part VI - Emotional motivations; Part VII - Economic and

124 availability motivations; Part VIII - Social and cultural motivations; Part IX -

125 Environmental and political motivations; Part $\mathrm{X}$ - Marketing and commercial 
126 motivations. These types of motivations were chosen because many different studies

127 somehow have indicated that eating habits and/or food choices are dependable on factors

128 such as the ones investigated through this questionnaire. The questionnaire was developed

129 and firstly validated on a sample of Portuguese people (Ferrão et al., 2018, 2019) and was

130 than extended into other countries as described in this work, after proper translation.

131 In order to measure the participants' opinions about the statements that were related

132 to the different types of motivations, they were asked to state their agreement measured 133 on a 5-point Likert scale varying from 1 (totally disagree) to 5 (totally agree) (Likert,

134 1932). Globally, 55 statements related to eating habits and the choice of a certain food

135 were compiled according to different motivations, as indicated: Healthy motivations -11

136 items; Emotional motivations - 10 items; Economic and availability motivations - 8

137 items; Social and cultural motivations - 11 items; Environmental and political 138 motivations - 8 items; Marketing and commercial motivations -7 items.

139

$140 \quad$ 2.2. Data collection

141 For the present study about the motivations in countries of the Mediterranean area, a

142 descriptive cross-sectional study was performed on a non-probabilistic sample with 4708

143 participants living in Portugal (28\%), Greece (11\%), Egypt (17\%), Croatia (33\%) and

144 Italy $(11 \%)$. The questionnaire was approved by the Ethical Committee (Reference $\mathrm{n}^{\mathrm{o}}$ 145 04/2017) before being applied. The data collection occurred between September 2017 146 and June 2018, and was addressed only to adults (aged 18 or over), after informed consent

147 was obtained and guaranteeing the confidentiality of the individual answers registered,

148 thus complying with all ethical issues necessary.

149

150

\subsection{Statistical analysis}


The exploratory analysis of the data was made by basic statistical tools. For each of

152 the six types of eating motivations considered, an average value was calculated from the

153 scores obtained in all the items included in that motivation category. The scores of the

154 original scale were recalculated so as to eliminate the effect of the middle point, which

155 became zero instead of 3 . Hence the scale for motivations varied from -2 to +2 , in which

156 the negative values meant "no influence" and the positive ones meant "influence".

157 So as to verify whether the mean values were statistically different between groups a 158 statistical analysis was applied. For comparisons between two groups the t-test for

159 independent samples was used, while for comparisons between three groups, was used 160 the Post-Hoc Tukey HSD (Honestly Significant Difference) coupled to an analysis of 161 variance (ANOVA). The use of parametric tests was possible because the conditions were 162 verified, namely the normality of the distribution and equality of variances according to 163 Levene's test. The analysis of the data was made by using SPSS software from IBM Inc., 164 Version 25 (Armonk, New York, USA) and in all tests the level of significance considered 165 was $5 \%$.

\section{RESULTS}

\section{$168 \quad$ 3.1. Sample characterization}

169 The sample was composed of 4708 participants, aged between 18 and 90 years old,

170 being on average $34.81 \pm 14.66$ years, from which $68.1 \%$ were female and $31.9 \%$ were

171 male. As it can be observed in Table 1, the participants were classified into age categories

172 according to: young adults $(18 \leq$ age $\leq 30)$, corresponding to $49.3 \%$; average adults (31

$173 \leq$ age $\leq 50)$, accounting for $32.7 \%$; senior adults $(51 \leq$ age $\leq 64)$, representing $15.4 \%$; and

174 finally elderly ( $\geq 65)$, which accounted for $2.6 \%$ of the sample. 
Table 1. Sociodemographic characterization.

Sociodemographic Data

Percentage (\%)

\begin{tabular}{|c|c|c|}
\hline \multirow[t]{4}{*}{ Age } & Young adults: $18 \leq$ age $\leq 30$ & 49.3 \\
\hline & Average adults: $31 \leq$ age $\leq 50$ & 32.7 \\
\hline & Senior adults: $51 \leq$ age $\leq 64$ & 15.4 \\
\hline & Elderly: Age $\geq 65$ & 2.6 \\
\hline \multirow[t]{2}{*}{ Gender } & Female & 68.1 \\
\hline & Male & 31.9 \\
\hline \multirow[t]{3}{*}{ Highest Level of Education } & Primary School & 2 \\
\hline & Secondary School & 38.5 \\
\hline & University Degree & 59.5 \\
\hline \multirow[t]{3}{*}{ Living Environment } & Rural & 21.2 \\
\hline & Urban & 66.9 \\
\hline & Sub-urban & 11.9 \\
\hline \multirow[t]{4}{*}{ Civil State } & Single & 48.2 \\
\hline & Married/Living Together & 45.4 \\
\hline & Divorced/Separated & 3.9 \\
\hline & Widow & 2.5 \\
\hline \multirow[t]{5}{*}{ Job Situation } & Student & 53.5 \\
\hline & Employed & 6.1 \\
\hline & Unemployed & 31.4 \\
\hline & Retired & 4.2 \\
\hline & Working student & 4.8 \\
\hline \multirow[t]{7}{*}{ Professional Area } & Nutrition & 3.9 \\
\hline & Food & 9.1 \\
\hline & Agriculture & 3.8 \\
\hline & Sport & 9 \\
\hline & Psychology & 2.7 \\
\hline & Health & 20.5 \\
\hline & Others & 51.0 \\
\hline
\end{tabular}

177

$178 \quad$ Most of the participants (59.5\%), had a university degree and only $2.0 \%$ of them had

179 the primary school as the highest level of education achieved. As for the civil state, $48.2 \%$

180 of the participants were single, $45.4 \%$ were married or lived together as a marital couple,

$1813.9 \%$ were divorced or separated and $2.5 \%$ were widowed. Regarding the living 
182 environment, the majority of the participants (66.9\%) lived in an urban environment,

183 followed by the participants who lived in rural areas, $21.2 \%$, and finally the ones who 184 lived in sub-urban surroundings, $11.9 \%$ (Table 1).

185 Concerning the job situation, most of the participants were students $(53.5 \%), 31.8 \%$ 186 were unemployed, $6.1 \%$ were employed, $4.8 \%$ were working students and $4.2 \%$ were

187 retired (Table 1). As for the participants' professional activity or field of studies, the 188 majority of the participants, $51 \%$, did not have a professional activity or field of studies 189 related to any of the options suggested in the questionnaire (nutrition, food science, 190 agriculture, sport, psychology, activities related to other health areas), $20.5 \%$ had a 191 professional activity or field of studies related to other health areas, $9.1 \%$ had a 192 professional activity or field of studies related to food, 9\% had a profession or studies 193 related to sports, $3.9 \%$ had a professional activity or field of studies related to nutrition, $1943.8 \%$ had a professional activity or field of studies related to agriculture and $2.7 \%$ had an 195 activity or studies in the psychology area.

196 Regarding the anthropometric data for the sample at study, the height was for the 197 whole sample on average $1.7 \pm 0.1$ meters $(1.65 \pm 0.07 \mathrm{~m}$ for women and $1.79 \pm 0.08 \mathrm{~m}$ 198 for men), and the weight was on average $68.64 \pm 14.34 \mathrm{~kg}(63.60 \pm 11.49 \mathrm{~kg}$ for women 199 and $79.22 \pm 13.87 \mathrm{~kg}$ for men). The Body Mass Index (BMI) was calculated as weight 200 (kg) divided by the square of height $\left(\mathrm{m}^{2}\right)$ and then classified according to the standards 201 of the International Classification: underweight $\left(\mathrm{BMI}<18.5 \mathrm{~kg} / \mathrm{m}^{2}\right)$, normal weight $(18.5$ $\left.202 \leq \mathrm{BMI} \leq 24.99 \mathrm{~kg} / \mathrm{m}^{2}\right)$, overweight $\left(25 \leq \mathrm{BMI} \leq 29.99 \mathrm{~kg} / \mathrm{m}^{2}\right)$ and obese $(\mathrm{BMI} \geq 30.00$ $203 \mathrm{~kg} / \mathrm{m}^{2}$ ) (World health Organization, 2006). The results showed that the BMI for the whole 204 sample was on average equal to $23.71 \pm 4.07 \mathrm{~kg} / \mathrm{m}^{2}$, which means that in general the 205 participants had a normal weight. When analysed by gender, it was observed that the 
average values for women were lower $\left(23.28 \pm 4.12 \mathrm{~kg} / \mathrm{m}^{2}\right)$ than those for men $(24.64 \pm$

$\left.2073.81 \mathrm{~kg} / \mathrm{m}^{2}\right)$.

208 Table 2 presents the BMI class according to country and it shows that, regardless of

209 the country, most of the participants had a normal weight. The results further showed that

210 Egypt had a considerable higher percentage of participants with overweight and obesity,

211 when compared to the other countries. Moreover, Portugal was the country with the

212 lowest percentage of participants classified as overweight or obese.

Table 2. Frequencies according to BMI Class.

\begin{tabular}{lccccc}
\hline BMI $^{\mathbf{1}}$ Class & $\begin{array}{c}\text { Portugal } \\
(\boldsymbol{\%})\end{array}$ & $\begin{array}{c}\text { Italy } \\
(\boldsymbol{\%})\end{array}$ & $\begin{array}{c}\text { Croatia } \\
(\boldsymbol{\%})\end{array}$ & $\begin{array}{c}\text { Greece } \\
(\boldsymbol{\%})\end{array}$ & $\begin{array}{c}\text { Egypt } \\
(\boldsymbol{\%})\end{array}$ \\
\hline Underweight $(\mathrm{BMI}<18.5)$ & 5.5 & 5.9 & 3.4 & 2.8 & 1.5 \\
\hline Normal Weight $(18.5 \leq \mathrm{BMI} \leq 24.9)$ & 79.3 & 63.2 & 59.9 & 68.3 & 49.3 \\
\hline Overweight $(25 \leq \mathrm{BMI} \leq 29.9)$ & 11.3 & 24.0 & 30.1 & 23.5 & 33.7 \\
\hline Obesity $(\mathrm{BMI} \geq 30)$ & 3.2 & 6.8 & 6.6 & 5.4 & 15.4 \\
\hline
\end{tabular}

$215 \quad{ }^{1} \mathrm{BMI}=$ Body Mass Index

Table 3 presents some of the behavioural aspects that characterize the sample at

218 study. According to the World Health Organization (WHO) (2018b), an inadequate level

219 of physical activity is one of the leading risk factors for death worldwide. In this study,

$22031.9 \%$ of the participants answered that they practiced physical exercise moderately and

221 only $9.8 \%$ of them practiced physical exercise intensively. On the other hand, a

222 reasonable percentage of the participants, $16.5 \%$, answered that they never practiced

223 physical activity, which is preoccupying attending to the importance of physical activity

224 to promote health at various levels.

225 As for the number of hours per day that the participants spent watching TV or at the 226 computer, it was observed that $30.9 \%$ spent between 0 to 2 hours on TV/computer per 
day, which is considered low, while $19.6 \%$ of the participants indicated that they spend more than 8 hours per day watching TV or at the computer, and in this case it is considered a very high utilisation of these screen technologies (Table 3). Nevertheless, these results must be interpreted with care, because no distinction was made in que questionnaire as to

231 the use of screens for leisure purposes and for work, in which case it cannot be avoided. A balanced diet is fundamental for the maintenance of health (Schwingshackl et al., 2018). Therefore, the participants were asked about how often they believed they practiced a balanced diet, and as it can be observed in Table 5, 37.8\% considered that they do it frequently, $36.6 \%$ sometimes, $12 \%$ rarely, $7.8 \%$ never while $5.8 \%$ of the participants considered that they always practice a balanced diet. This questions intended to make a self-evaluation of their own eating patterns, but it was based on each one's individual perception of what they consider to be a healthy diet. Therefore, the results must be read as defining an approximation to a heathy diet.

The results in Table 3 further showed that most of the participants, $77.4 \%$, did not

241 follow any specific food regimen. It is interesting to highlight that more women, $8.6 \%$,

242 followed a dietary regimen based on a caloric restriction, when compared to men, $6 \%$.

243 These results are not surprising, since women are more likely to be dissatisfied with their 244 body image than men and therefore they have a greater tendency to adopt dietary regimens that stimulate weight loss (Germov and Williams, 2017). 
Table 3. Behavioural aspects.

\begin{tabular}{|c|c|c|}
\hline Behavioural aspects & & Percentage (\%) \\
\hline Physical Exercise & Never & 16.5 \\
\hline & Sporadically (< 1 time/week) & 22.1 \\
\hline & Occasionally (1 time/week) & 19.7 \\
\hline & Moderately (2-3 times/week) & 31.9 \\
\hline & Intensively (> 3 times/week) & 9.8 \\
\hline Hours of TV/Computer/day & Low: $[0-2] \mathrm{h}$ & 30.9 \\
\hline & Medium: ]2-4] h & 25.5 \\
\hline & High: ]4 - 8] h & 24 \\
\hline & Very high: $>8 \mathrm{~h}$ & 19.6 \\
\hline Frequency of balanced diet & Never & 7.8 \\
\hline & Rarely & 12 \\
\hline & Sometimes & 36.6 \\
\hline & Frequently & 37.8 \\
\hline & Always & 5.8 \\
\hline Dietary regimen & Raw Foodism & 1.7 \\
\hline & Frutarianism & 0.9 \\
\hline & Vegetarianism & 2.4 \\
\hline & Veganism & 1 \\
\hline & Flexitarianism & 5.8 \\
\hline & Caloric restriction & 7.8 \\
\hline & Religious restriction & 1 \\
\hline & Other & 2.1 \\
\hline & No specific diet & 77.4 \\
\hline
\end{tabular}

Table 4 presents some health conditions that characterize the sample at study. The

252 results indicate that the majority of the participants, $74.5 \%$, did not have any chronic

253 disease. The fact that most of the participants were aged under 50 years old certainly is

254 one of the factors explaining this result, allied to a possible adherence to the

255 Mediterranean Diet, whose benefits to prevent and fight chronic diseases are documented

256 (Dohrmann et al., 2018; Ndlovu et al., 2018; Serra-Majem et al., 2019). As for the 
257 participants' food allergies or intolerances, it was observed that the majority (86.9\%) did 258 not suffer from any food allergy or intolerance.

259

Table 4. Health aspects.

\begin{tabular}{|c|c|c|c|}
\hline \multirow[t]{2}{*}{ Health aspects } & & \multicolumn{2}{|c|}{ Percentage (\%) } \\
\hline & & YES & NO \\
\hline \multirow[t]{9}{*}{ Chronic Diseases } & Cardiovascular diseases & 3 & 97 \\
\hline & Diabetes & 1.7 & 98.3 \\
\hline & High cholesterol & 6.7 & 93.3 \\
\hline & Arterial hypertension & 8.5 & 91.5 \\
\hline & Gastric disorders & 4.4 & 95.6 \\
\hline & Intestinal disorders & 2.1 & 97.9 \\
\hline & Obesity & 2.5 & 97.5 \\
\hline & Other & 4.9 & 95.1 \\
\hline & No chronic diseases & 74.5 & 25.5 \\
\hline \multirow[t]{7}{*}{ Food Allergy/Intolerance } & Lactose & 4.6 & 95.4 \\
\hline & Casein & 0.8 & 99.2 \\
\hline & Gluten & 1.4 & 98.6 \\
\hline & Nuts & 1.1 & 98.9 \\
\hline & Shellfish & 3.9 & 96.1 \\
\hline & Other & 2.6 & 97.4 \\
\hline & No allergies or intolerances & 86.9 & 13.1 \\
\hline \multirow[t]{5}{*}{ Eating disorders } & Bulimia nervosa & 1 & 99 \\
\hline & Anorexia nervosa & 5.5 & 94.5 \\
\hline & Binge-eating & 4.4 & 95.6 \\
\hline & Other & 0.5 & 99.5 \\
\hline & No eating disorders & 88.6 & 11.4 \\
\hline
\end{tabular}

262 From the sample at study, $88.6 \%$ of the participants answered that they never had an

263 episode of any eating disorder (Table 4). As for those who had experienced one, the most

264 frequent was anorexia nervosa, at least once by $5.5 \%$ of the participants. When seen by

265 gender, it was observed that a higher percentage of women already suffered from at least

266 one eating disorder (bulimia nervosa: 1.4\%; anorexia nervosa: 6.4\%; binge-eating: 4.8\%; 
267 other: $0.6 \%$ ) when compared to men (bulimia nervosa: $0.3 \%$; anorexia nervosa: $3.5 \%$;

268 binge-eating: 3.4\%; other: $0.2 \%$ ). In fact, eating disorders are reported to be more 269 common among women than men (Murray et al., 2017).

270 One other important factor related to food choice is depending whether people are 271 responsible for buying their own food. In this study, $83.3 \%$ of the participants bought 272 their own food while only $16.79 \%$ did not, being this percentage higher for women (87\%) 273 than for men $(75.6 \%)$.

\subsection{Eating motivations}

Table 5 presents the participants' eating motivations by country and, in general

277 regardless of the country, the participants' food choices were not heavily influenced by 278 any of the considered types of motivations. For Portugal and Italy, the participants' food 279 choices were more influenced by environmental and political motivations, while in 280 Croatia and Egypt the most important motivation was health, and in Greece the 281 participants' were more influenced by health, as well as environmental and political 282 motivations. The results of the ANOVA test showed that those differences between 283 countries were statistically significant (Health: $\mathrm{F}=113.577, \mathrm{p}<0.001$; Emotional: $\mathrm{F}=$ 284 82.377, $\mathrm{p}<0.001$; Economic and availability: $\mathrm{F}=66.832, \mathrm{p}<0.001$; Social and cultural: $285 \mathrm{~F}=174.475, \mathrm{p}<0.001 ;$ Environmental and political: $\mathrm{F}=193.268, \mathrm{p}<0.001 ;$ Marketing 286 and commercial: $\mathrm{F}=238.103, \mathrm{p}<0.001)$. These results are not surprising since health is 287 an important determinant for people's food choices (Birkenhead and Slater, 2015). 288 Additionally to health motivations, consumers' are more conscientious about the impact 289 of their diets on the environment and also about the importance of adopting diets that are 290 more sustainable from an environmental point of view (Hoek et al., 2017). In a study by 291 Markovina et al. (Markovina et al., 2015) it was found that the most important food choice 
292 motivation in Portugal and Greece was the price, which does not agree with the finding

293 in this work. However, it is worth mention that the cited study was dated from 2015 and,

294 due to greater alert to the consequences of climate change and pollution effects, the

295 environmental factors may be overcoming those of commodity or even price, because

296 people attribute value to intangible values linked to the preservation of the natural

297 biosystems. Furthermore, the differences between countries could be partially explained

298 by the variations in the climate, geography, socioeconomic factors, culture and history of

299 the countries involved in the study (Hoffman and Gerber, 2013).

300

301

Table 5. Motivations by country and physical exercise.

\begin{tabular}{lccccc}
\hline \multirow{2}{*}{ Type of motivations } & \multicolumn{3}{c}{ Country $^{1}$} \\
\cline { 2 - 5 } & Portugal & Italy & Croatia & Greece & Egypt \\
\hline Health & $0.7 \pm 0.5^{\mathrm{c}}$ & $0.4 \pm 0.5^{\mathrm{a}}$ & $0.4 \pm 0.6^{\mathrm{a}}$ & $0.3 \pm 0.6^{\mathrm{a}}$ & $0.5 \pm 0.5^{\mathrm{b}}$ \\
\hline Emotional & $-0.3 \pm 0.5^{\mathrm{a}}$ & $0.0 \pm 0.7^{\mathrm{b}}$ & $-0.2 \pm 0.7^{\mathrm{a}}$ & $0.0 \pm 0.7^{\mathrm{b}}$ & $-0.3 \pm 0.7^{\mathrm{c}}$ \\
\hline Economic and availability & $0.0 \pm 0.4^{\mathrm{b}}$ & $-0.1 \pm 0.5^{\mathrm{a}}$ & $0.1 \pm 0.5^{\mathrm{c}}$ & $-0.1 \pm 0.5^{\mathrm{a}}$ & $0.2 \pm 0.6^{\mathrm{d}}$ \\
\hline Social and cultural & $-0.1 \pm 0.4^{\mathrm{b}}$ & $-0.1 \pm 0.4^{\mathrm{b}}$ & $-0.1 \pm 0.5^{\mathrm{b}}$ & $-0.3 \pm 0.5^{\mathrm{a}}$ & $0.3 \pm 0.5^{\mathrm{c}}$ \\
\hline Environmental and political & $0.8 \pm 0.5^{\mathrm{e}}$ & $0.6 \pm 0.6^{\mathrm{d}}$ & $0.1 \pm 0.7^{\mathrm{a}}$ & $0.3 \pm 0.7^{\mathrm{b}}$ & $0.4 \pm 0.6^{\mathrm{c}}$ \\
\hline Marketing and commercial & $-0.6 \pm 0.6^{\mathrm{a}}$ & $-0.5 \pm 0.5^{\mathrm{b}}$ & $-0.2 \pm 0.5^{\mathrm{d}}$ & $-0.4 \pm 0.6^{\mathrm{c}}$ & $0.1 \pm 0.5^{\mathrm{e}}$
\end{tabular}

Physical activity ${ }^{1}$

\begin{tabular}{lccccr} 
Type of motivations & Never & $\begin{array}{c}\text { Sporadic } \\
<\mathbf{1 / w e e k}\end{array}$ & $\begin{array}{c}\text { Occasional } \\
\mathbf{1 / w e e k}\end{array}$ & $\begin{array}{c}\text { Moderate } \\
\mathbf{2 - 3 / w e e k}\end{array}$ & $\begin{array}{c}\text { Intense } \\
>3 / \text { week }\end{array}$ \\
\hline Health & $0.3 \pm 0.6^{\mathrm{a}}$ & $0.4 \pm 0.5^{\mathrm{a}}$ & $0.5 \pm 0.5^{\mathrm{b}}$ & $0.7 \pm 0.5^{\mathrm{d}}$ & $0.6 \pm 0.6^{\mathrm{c}}$ \\
\hline Emotional & $0.1 \pm 0.7^{\mathrm{c}}$ & $-0.1 \pm 0.7^{\mathrm{bc}}$ & $-0.1 \pm 0.7^{\mathrm{b}}$ & $-0.2 \pm 0.6^{\mathrm{a}}$ & $-0.2 \pm 0.7^{\mathrm{a}}$ \\
\hline Economic and availability & $0.1 \pm 0.6^{\mathrm{b}}$ & $0.1 \pm 0.5^{\mathrm{b}}$ & $0.1 \pm 0.5^{\mathrm{b}}$ & $0.0 \pm 0.4^{\mathrm{a}}$ & $0.0 \pm 0.5^{\mathrm{a}}$ \\
\hline Social and cultural & $0.0 \pm 0.6^{\mathrm{b}}$ & $-0.1 \pm 0.5^{\mathrm{a}}$ & $-0.1 \pm 0.5^{\mathrm{a}}$ & $-0.1 \pm 0.5^{\mathrm{a}}$ & $-0.1 \pm 0.5^{\mathrm{a}}$ \\
\hline Environmental and political & $0.4 \pm 0.7^{\mathrm{a}}$ & $0.3 \pm 0.7^{\mathrm{a}}$ & $0.4 \pm 0.7^{\mathrm{a}}$ & $0.6 \pm 0.6^{\mathrm{b}}$ & $0.4 \pm 0.7^{\mathrm{a}}$ \\
\hline Marketing and commercial & $-0.1 \pm 0.6^{\mathrm{d}}$ & $-0.3 \pm 0.6^{\mathrm{c}}$ & $-0.3 \pm 0.6^{\mathrm{c}}$ & $-0.6 \pm 0.6^{\mathrm{a}}$ & $-0.4 \pm 0.6^{\mathrm{b}}$
\end{tabular}

$302{ }^{1}$ Scale from -2 (no influence) to +2 (very high influence); all values stand for mean \pm standard deviation; 303 values in the same line with the same superscript are not statistically different, ANOVA with Tukey HSD 304 post-hoc test (level of significance 5\%). 
307 As it can be observed in Table 5, which relates also eating motivations with physical 308 activity, the motivation with a higher average score was health, $0.7 \pm 0.5$, for the 309 participants who practiced physical activity moderately (2-3 times per week). Moreover,

310 the results also showed that the participants who practiced physical activity moderately

311 seemed to have more environmental and political concerns when choosing their food

$312(0.6 \pm 0.6)$. On the other hand, the participants who practiced physical activity moderately

313 were less influenced by emotional, social \& cultural or marketing \& commercial

314 motivations. The results of the ANOVA test showed that the differences between groups

315 were statically significant (Health: $F=98.949, p<0.001$; Emotional: $F=24.870, p$

$316<0.001$; Economic and availability: $F=16.336, p<0.001$; Social and cultural: $F=9.339$,

$317 \mathrm{p}<0.001$; Environmental and political: $\mathrm{F}=45.606, \mathrm{p}<0.001$; Marketing and commercial:

$318 \mathrm{~F}=112.735, \mathrm{p}<0.001)$. Another interesting result is the fact that the food choices of the

319 participants who practiced physical activity moderately or intensively were less

320 influenced by emotional concerns, when compared to the other groups of physical

321 activity. In the study of Loprinzi and his colleagues (Loprinzi et al., 2014) it was found

322 that the participants who practiced physical activity according to the guidelines provided

323 by the authors of that study were more likely to adopt a healthy diet.

324 Table 6 shows the participants' eating motivations according to gender and, as it can

325 be observed, for women the most important motivation was health, while men's food

326 choices were mainly influenced by health as well as environmental and political concerns.

327 The results of the T-test showed that those differences between genders were statistically 328 significant for almost every type of motivation, with the exception of social and cultural 329 motivations $(\mathrm{p}=0.21)$. Nevertheless, since the average scores were always lower than

3301.5 , for both men and women, their food choices were not much influenced by none of 
331 the considered types of motivation. These results are in line with previous research, where

332 it was also found that, in general, women are more concerned with their diet, weight and

333 health control (Johansen et al., 2011) and therefore they have a greater tendency to have

334 strong positive motivations towards eating a healthy diet (Naughton et al., 2015).

335

Table 6. Motivations by Gender and dietary regimen.

\begin{tabular}{lcccc}
\hline \multirow{2}{*}{ Type of motivations } & \multicolumn{2}{c}{ Gender $^{\mathbf{2}}$} & & T-test $^{\mathbf{2}}$ \\
\cline { 2 - 3 } & Female & Male & & p-value \\
\hline Health & $0.6 \pm 0.5$ & $0.4 \pm 0.6$ & $<0.001$ \\
\hline Emotional & $0.0 \pm 0.7$ & $-0.2 \pm 0.6$ & $<0.001$ \\
\hline Social and cultural & $0.0 \pm 0.5$ & $0.0 \pm 0.5$ & 0.033 \\
\hline Environmental and political & $0.0 \pm 0.5$ & $-0.1 \pm 0.5$ & 0.21 \\
\hline Marketing and commercial & $0.5 \pm 0.6$ & $0.4 \pm 0.7$ & $<0.001$ \\
\hline Type of motivations & $-0.3 \pm 0.6$ & $-0.4 \pm 0.6$ & 0.001 \\
\hline Health & Dietary regimen & T-test \\
\cline { 2 - 3 } & Special Diet & No Special diet & p-value \\
\hline Emotional & $0.6 \pm 0.5$ & $0.5 \pm 0.6$ & $<0.001$ \\
\hline Economic and availability & $0.0 \pm 0.7$ & $-0.1 \pm 0.7$ & $<0.001$ \\
\hline Social and cultural & $0.1 \pm 0.5$ & $0.1 \pm 0.5$ & 0.218 \\
\hline Environmental and political & $0.0 \pm 0.5$ & $-0.1 \pm 0.5$ & 0.052 \\
\hline Marketing and commercial & $-0.3 \pm 0.6$ & $-0.4 \pm 0.6$ & $<0.001$ \\
\hline
\end{tabular}

${ }^{1}$ Scale from -2 (no influence) to +2 (very high influence); The values stand for mean \pm standard
deviation. ${ }^{2} \mathrm{~T}$-test for independent samples (level of significance $5 \%$ ).

Since people's dietary regimen is one of the determinants that affects their food choices (Hoefkens et al., 2011), it was also analysed if there were differences in the participants' food choices according to their dietary regimen. Table 6 also presents the participants' motivations for food choices by dietary regimen and, in general, the food choices of the participants who followed a special diet were more influenced by different factors when compared with people with a regular diet. The major motivation for the food 
346 choices of the participants who followed a special diet was health $(0.6 \pm 0.5)$, being this

347 significantly higher than for who did not follow any special diet $(0.5 \pm 0.6)$. This finding

348 indicates that the participants were aware of the impact of dietary patterns on the

349 development or prevention of diseases, so much that those who followed a special diet

350 did it strongly motivated by health concerns. Many published studies associate special

351 diets with health issues (Braha et al., 2017; Coelho et al., 2019; Guallar-Castillón et al.,

352 2012; Lavallee et al., 2019; Satija and Hu, 2018; Yu et al., 2018). The results of the T-

353 test showed that the differences in the food choice motivations according to the

354 participants' dietary regimen were statistically significant, with the exception of the

355 economic \& availability motivations $(\mathrm{p}=0.218)$, as well as social $\&$ cultural motivations

$356 \quad(\mathrm{p}=0.052)$.

357 As it can be observed in Table 7 the food choices of the participants who had chronic 358 diseases were more influenced by health motivations $(0.5 \pm 0.5)$, followed by the 359 environmental and political motivations $(0.4 \pm 0.7)$. For the participants who did not have 360 any chronic disease, the major determinants for their food choices were health $(0.6 \pm 0.6)$

361 and also environmental \& political concerns $(0.6 \pm 0.7)$. Furthermore, the average score

362 for the health motivations among the participants who did not have any chronic disease 363 was higher when compared to those who suffered from chronic diseases, meaning that 364 having a health problem might not be motivating enough to eat healthier. Therefore, it 365 might be due to inappropriate food choices that these diseases arise and progress in these 366 individuals, who are reckless regarding their health. Again there were found significant 367 differences in the food choice motivations of the participants who had chronic diseases 368 and those who had not, with the exception of economic \& availability motivations ( $\mathrm{p}=$ 369 0.438), as well as environmental \& political motivations $(\mathrm{p}=0.631)$. According to other 370 studies, having a chronic disease is a factor that may change people's eating habits and 
371 prompt them to eat healthier. For example, in the study developed by Ghelfi et al. (Ghelfi

372 et al., 2018), cancer patients and long-term survivors are known to be more sensitive to

373 health-related information and dietary changes.

374

375

Table 7. Motivations by chronic diseases, allergies/intolerances and eating disorders.

\begin{tabular}{|c|c|c|c|}
\hline \multirow[b]{2}{*}{ Type of motivations } & \multicolumn{2}{|c|}{ Average value for each group ${ }^{1}$} & \multirow{2}{*}{$\begin{array}{c}\text { T-test }{ }^{2} \\
\text { p-value }\end{array}$} \\
\hline & $\begin{array}{l}\text { Chronic } \\
\text { diseases }\end{array}$ & $\begin{array}{c}\text { No chronic } \\
\text { diseases }\end{array}$ & \\
\hline Health & $0.5 \pm 0.5$ & $0.6 \pm 0.6$ & $<0.001$ \\
\hline Emotional & $-0.1 \pm 0.7$ & $-0.1 \pm 0.7$ & 0.007 \\
\hline Economic and availability & $0.1 \pm 0.5$ & $0.1 \pm 0.5$ & 0.438 \\
\hline Social and cultural & $0.0 \pm 0.5$ & $0.0 \pm 0.5$ & 0.631 \\
\hline Environmental and political & $0.4 \pm 0.7$ & $0.6 \pm 0.7$ & $<0.001$ \\
\hline \multirow[t]{2}{*}{ Marketing and commercial } & $-0.3 \pm 0.6$ & $-0.5 \pm 0.6$ & $<0.001$ \\
\hline & \multicolumn{2}{|c|}{ Allergies/intolerances $^{1}$} & T-test ${ }^{2}$ \\
\hline Type of motivations & $\begin{array}{c}\text { Allergies/ } \\
\text { intolerances }\end{array}$ & $\begin{array}{l}\text { No allergies/ } \\
\text { intolerances }\end{array}$ & p-value \\
\hline Health & $0.5 \pm 0.5$ & $0.6 \pm 0.5$ & $<0.001$ \\
\hline Emotional & $-0.1 \pm 0.7$ & $-0.1 \pm 0.7$ & 0.136 \\
\hline Economic and availability & $0.1 \pm 0.6$ & $0.1 \pm 0.5$ & 0.031 \\
\hline Social and cultural & $0.0 \pm 0.5$ & $0.0 \pm 0.5$ & 0.669 \\
\hline Environmental and political & $0.4 \pm 0.7$ & $0.6 \pm 0.7$ & $<0.001$ \\
\hline \multirow[t]{2}{*}{ Marketing and commercial } & $-0.4 \pm 0.6$ & $-0.4 \pm 0.7$ & $<0.001$ \\
\hline & \multicolumn{2}{|c|}{ Eating disorders $^{1}$} & T-test ${ }^{2}$ \\
\hline Type of motivations & $\begin{array}{c}\text { Eating } \\
\text { disorders }\end{array}$ & $\begin{array}{l}\text { No eating } \\
\text { disorders }\end{array}$ & p-value \\
\hline Health & $0.4 \pm 0.5$ & $0.5 \pm 0.5$ & $<0.001$ \\
\hline Emotional & $0.2 \pm 0.7$ & $-0.1 \pm 0.6$ & $<0.001$ \\
\hline Economic and availability & $0.2 \pm 0.5$ & $0.0 \pm 0.5$ & $<0.001$ \\
\hline Social and cultural & $0.1 \pm 0.5$ & $-0.1 \pm 0.5$ & $<0.001$ \\
\hline Environmental and political & $0.4 \pm 0.6$ & $0.5 \pm 0.7$ & 0.112 \\
\hline Marketing and commercial & $-0.1 \pm 0.6$ & $-0.4 \pm 0.6$ & $<0.001$ \\
\hline
\end{tabular}

${ }^{1}$ Scale from -2 (no influence) to +2 (very high influence); The values stand for mean \pm standard 
According to Sommer et al. (2012), approximately 35\% of the population modify their diet because of adverse reactions to food. In the present study, not surprisingly, there were found significant differences between the food choices of the participants who had food allergies or intolerances and those who had not, regarding the health motivations ( $\mathrm{p}$ $<0.001)$, economic \& availability motivations $(\mathrm{p}=0.031)$, environmental \& political concerns $(\mathrm{p}<0.001)$ and marketing \& commercial motivations $(\mathrm{p}<0.001)$ (Table 7). The results further showed that the food choices of the participants who had food allergies/intolerances were primarily affected by health motivations $(0.5 \pm 0.5)$, while the food choices of those who had not were more affected by health $(0.6 \pm 0.5)$, as well as environmental \& political determinants $(0.6 \pm 0.7)$. However, it is important to refer that the food choices of the participants who did not have allergies or food intolerances were

390 affected by health concerns to a higher extent, when compared to those who suffered from them. This is a surprising result and, up to our knowledge, no previous works were found that could explain this, since people with problems motivated by the ingestion of certain types of food should be more careful as to what they eat and the impact on their wel-

394 being.

Table 7 further shows the participants' eating motivations according to their eating disorders and, for those who already suffered from an episode of any eating disorder, the main motivations for their food choices were health $(0.4 \pm 0.5)$, as well as environmental \& political concerns $(0.4 \pm 0.6)$, this trend being similar for the participants who never 399 suffered from any eating disorder (health motivations: $0.5 \pm 0.5$; environmental and 400 political motivations: $0.5 \pm 0.7)$. With the exception of environmental \& political 401 motivations, there were found significant differences in the eating motivations of the participants who already had an episode of an eating disorder and those who never had. 
emotional motivations $(0.2 \pm 0.7)$, when compared to those who never had $(-0.1 \pm 0.6)$.

405 These results are in line with previous studies, where it was also found that eating driven

406 by emotional reasons is more common among those who already suffered from an eating

407 disorder (Boggiano et al., 2017).

408

409

\section{CONCLUSION}

410 In general, regardless the variable analysed, the participants' food choices were more

411 strongly influenced by health and environmental \& political motivations. The

412 participants' eating motivations varied across countries and while in Portugal and Italy

413 the participants' food choices were more influenced by environmental \& political

414 concerns, in Croatia and Egypt it was health the major determinant and in Greece the

415 participants' food choices were more influenced by health, as well as environmental \&

416 political motivations. These results highlighted the importance that the Mediterranean

417 countries attribute to health and the sustainability of their diets. In addition, it was also

418 possible to perceive that those differences in the eating motivations between countries

419 were statistically significant.

420 Factors such as gender, level of physical activity, dietary regimen, absence of a

421 chronic disease, presence of food allergies or intolerances and the fact that the participants

422 had already experienced an episode of an eating disorder, were proved to influence the

423 participants' food choices. This research has also shown that women tended to be more

424 influenced by eating motivations than men, with significant differences between genders,

425 and that the participants who practiced physical activity moderately were more concerned

426 about the health and sustainability of their diets than with emotional, social, or even

427 marketing issues. There were also observed significant differences between the 428 participants who adopted a special diet and those who did not, so that the food choices of 
those who followed a specific dietary regimen were more influenced by eating

430 motivations. Moreover, the participants who already suffered from an eating disorder

431 tended to be more influenced by emotional motivations than those who had not, with

432 significant differences between the two groups. The absence of chronic diseases or food

433 intolerances/allergies also showed to have an influence on the participants' food choices,

434 so that those who did not have any chronic disease or food intolerance/allergy were more

435 influenced by health motivations, when compared to the participants who had them.

436 One of the limitations of this study was the low number of countries included in the

437 study as a sample of the Mediterranean Countries, which are far more. Five was the

438 possible number of countries, even though more countries were invited but chose not to

439 participate in the study. One other limitation was the representability in each of the

440 participating countries, which was not equalitarian in terms of the stratified groups of the

441 population. Also, the number of responses obtained in each of the countries was highly

442 variable, and not proportional to the country size.

443 The results of this study are very important, because they pointed the complexity that

444 is involved in people's food choices and highlighted different factors that influence those

445 choices. These findings are fundamental to the development of policies and strategies that 446 encourage people to adopt healthier dietary patterns. These actions could be implemented

447 at national levels or even in the ambit of multinational policies aimed to diminish the 448 burden of chronic diseases.

449 Although this work highlights some trends that characterize the general factors 450 influencing the food choices around the Mediterranean, further research is necessary, and 451 in the ambit of the ongoing project some similar studies are being undertaken in other 452 countries, all around Europe and also in America and African countries. 


\section{Acknowledgment}

455 This work was prepared in the ambit of the multinational project EATMOT from 456 CI\&DETS Research Centre (IPV - Viseu, Portugal) with reference PROJ/CI\&DETS/CGD/0012, co-financed by Caixa Geral de Depósitos.

\section{References}

Barauskaite, D., Gineikiene, J., Fennis, B.M., Auruskeviciene, V., Yamaguchi, M. and Kondo, N. (2018), "Eating healthy to impress: How conspicuous consumption, perceived self-control motivation, and descriptive normative influence determine functional food choices", Appetite, Vol. 131, pp. 59-67.

Barrea, L., Muscogiuri, G., Di Somma, C., Tramontano, G., De Luca, V., Illario, M., Colao, A., et al. (2018), “Association between Mediterranean diet and hand grip strength in older adult women", Clinical Nutrition, available at:https://doi.org/10.1016/j.clnu.2018.03.012.

Birkenhead, K.L. and Slater, G. (2015), “A Review of Factors Influencing Athletes’ Food Choices”, Sports Medicine, Vol. 45 No. 11, pp. 1511-1522.

Boccardi, V., Calvani, R., Limongi, F., Marseglia, A., Mason, A., Noale, M., Rogoli, D., et al. (2018), "Consensus paper on the 'executive summary of the international conference on Mediterranean diet and health: a lifelong approach' an Italian initiative supported by the Mediterranean Diet Foundation and the Menarini Foundation", Nutrition, Vol. 51-52, pp. 38-45.

Boggiano, M.M., Wenger, L.E., Burgess, E.E., Tatum, M.M., Sylvester, M.D., Morgan, P.R. and Morse, K.E. (2017), "Eating tasty foods to cope, enhance reward, 
socialize or conform: What other psychological characteristics describe each of these motives?", Journal of Health Psychology, Vol. 22 No. 3, pp. 280-289.

Braha, K., Cupák, A., Pokrivčák, J., Qineti, A. and Rizov, M. (2017), “Economic analysis of the link between diet quality and health: Evidence from Kosovo", Economics \& Human Biology, Vol. 27, pp. 261-274.

van Buul, V.J., Bolman, C.A.W., Brouns, F.J.P.H. and Lechner, L. (2017), “Back-of-pack information in substitutive food choices: A process-tracking study in participants intending to eat healthy", Appetite, Vol. 116, pp. 173-183.

Castro-Quezada, I., Román-Viñas, B., Serra-Majem, L., Castro-Quezada, I., RománViñas, B. and Serra-Majem, L. (2014), “The Mediterranean Diet and Nutritional Adequacy: A Review”, Nutrients, Vol. 6 No. 1, pp. 231-248.

Coelho, M.S., Fernandes, S.S. and Salas-Mellado, M. de las M. (2019), "Chapter 9 Association Between Diet, Health, and the Presence of Bioactive Compounds in Foods", in Campos, M.R.S. (Ed.), Bioactive Compounds, Woodhead Publishing, pp. 159-183.

Dohrmann, D.D., Putnik, P., Kovačević, D.B., Simal-Gandara, J., Lorenzo, J.M. and Barba, F.J. (2018), "Japanese, Mediterranean and Argentinean diets and their potential roles in neurodegenerative diseases", Food Research International, available at:https://doi.org/10.1016/j.foodres.2018.10.090.

Ferrão, A.C., Guiné, R.P.F., Correia, P., Ferreira, M., Cardoso, A.P., Duarte, J. and Lima, J. (2018), "Perceptions towards a healthy diet among a sample of university people in Portugal”, Nutrition \& Food Science, Vol. 48 No. 4, pp. 669-688. 
Ferrão, A.C., Guine, R.P.F., Correia, P.M.R., Ferreira, M. and Lima, J.D. and J. (2019), "Development of A Questionnaire To Assess People's Food Choices Determinants", Current Nutrition \& Food Science, Vol. (in press), available at: http://www.eurekaselect.com/157301/article (accessed 19 November 2018).

Germov, J. and Williams, L. (2017), "Dieting Women - Self-Surveillance and the Body Panopticon", in Sobal, J. (Ed.), Weighty Issues - Fatness and Thinness as Social

Ghelfi, F., Tieri, M., Gori, S., Nicolis, F., Petrella, M.C., Filiberti, A., Apolone, G., et al. (2018), "Do cancer patients change their diet in the e-health information era? A Problems, Routledge, p. 16.

Grosso, G., Mistretta, A., Frigiola, A., Gruttadauria, S., Biondi, A., Basile, F., Vitaglione, P., et al. (2014), "Mediterranean diet and cardiovascular risk factors: a systematic review.", Critical Reviews in Food Science and Nutrition, Vol. 54 No. 5, pp. 593-

Guallar-Castillón, P., Rodríguez-Artalejo, F., Tormo, M.J., Sánchez, M.J., Rodríguez, L., Quirós, J.R., Navarro, C., et al. (2012), "Major dietary patterns and risk of

519 Hoefkens, C., Verbeke, W. and Van Camp, J. (2011), “European consumers' perceived coronary heart disease in middle-aged persons from a Mediterranean country: The EPIC-Spain cohort study", Nutrition, Metabolism and Cardiovascular Diseases, importance of qualifying and disqualifying nutrients in food choices", Food Quality and Preference, Vol. 22 No. 6, pp. 550-558. 
522 Hoek, A.C., Pearson, D., James, S.W., Lawrence, M.A. and Friel, S. (2017), "Shrinking

Hoffman, R. and Gerber, M. (2013), The Mediterranean Diet: Health and Science, John Wiley \& Sons.

Johansen, S.B., Næs, T. and Hersleth, M. (2011), "Motivation for choice and healthiness

Leng, G., Adan, R.A.H., Belot, M., Brunstrom, J.M., Graaf, K. de, Dickson, S.L., Hare, T., et al. (2017), "The determinants of food choice", Proceedings of the Nutrition Society, Vol. 76 No. 3, pp. 316-327. 
545 Likert, R. (1932), "A technique for the measurement of attitudes", Archives of $546 \quad$ Psychology, Vol. 22 140, p. 55.

547 Loprinzi, P.D., Smit, E. and Mahoney, S. (2014), "Physical Activity and Dietary Behavior in US Adults and Their Combined Influence on Health", Mayo Clinic Proceedings, Vol. 89 No. 2, pp. 190-198.

Mai, R. and Hoffmann, S. (2014), "How to Combat the Unhealthy= Tasty Intuition: The Influencing Role of Health Consciousness", Journal of Public Policy \& Marketing, Vol. 34 No. 1, pp. 63-83.

Markovina, J., Stewart-Knox, B.J., Rankin, A., Gibney, M., de Almeida, M.D.V., Fischer, A., Kuznesof, S.A., et al. (2015), "Food4Me study: Validity and reliability of Food Choice Questionnaire in 9 European countries", Food Quality and Preference, Vol. 45, pp. 26-32.

Murray, S.B., Nagata, J.M., Griffiths, S., Calzo, J.P., Brown, T.A., Mitchison, D., 558 Blashill, A.J., et al. (2017), "The enigma of male eating disorders: A critical review and synthesis", Clinical Psychology Review, Vol. 57, pp. 1-11.

Naughton, P., McCarthy, S.N. and McCarthy, M.B. (2015), “The creation of a healthy eating motivation score and its association with food choice and physical activity in a cross sectional sample of Irish adults", The International Journal of Behavioral Nutrition and Physical Activity, Vol. 12, available at:https://doi.org/10.1186/s12966-015-0234-0.

Ndlovu, T., van Jaarsveld, F. and Caleb, O.J. (2018), "French and Mediterranean-style diets: Contradictions, misconceptions and scientific facts-A review", Food 
at:https://doi.org/10.1016/j.foodres.2018.09.020.

569

570

571

572

573

574

575

576

577

578

580

581

582

583

584

Organ, K., Koenig-Lewis, N., Palmer, A. and Probert, J. (2015), "Festivals as agents for behaviour change: A study of food festival engagement and subsequent food choices", Tourism Management, Vol. 48, pp. 84-99.

Ostan, R., Lanzarini, C., Pini, E., Scurti, M., Vianello, D., Bertarelli, C., Fabbri, C., et al. (2015), "Inflammaging and cancer: a challenge for the Mediterranean diet", Nutrients, Vol. 7 No. 4, pp. 2589-2621.

Park, S.-Y., Murphy, S.P., Wilkens, L.R., Yamamoto, J.F., Sharma, S., Hankin, J.H., Henderson, B.E., et al. (2005), “Dietary patterns using the Food Guide Pyramid groups are associated with sociodemographic and lifestyle factors: the multiethnic cohort study", The Journal of Nutrition, Vol. 135 No. 4, pp. 843-849.

Pelly, F.E., Burkhart, S.J. and Dunn, P. (2018), "Factors influencing food choice of athletes at international competition events", Appetite, Vol. 121, pp. 173-178.

Renzella, J., Townsend, N., Jewell, J., Breda, J., Roberts, N., Rayner, M. and Wickramasinghe, K. (2018), What National and Subnational Interventions and Policies Based on Mediterranean and Nordic Diets Are Recommended or Implemented in the WHO European Region, and Is There Evidence of Effectiveness in Reducing Noncommunicable Diseases?, WHO Regional Office for Europe, Copenhagen, available at: http://europepmc.org/abstract/med/30091868 (accessed 23 October 2018).

Rozin, P. (2007), "How does culture affect choice of foods?", Consumer-Led Food Product Development, pp. 66-80. 
590 Satija, A. and Hu, F.B. (2018), "Plant-based diets and cardiovascular health", Trends in Cardiovascular Medicine, Vol. 28 No. 7, pp. 437-441.

592 Schwingshackl, L., Bogensberger, B. and Hoffmann, G. (2018), "Diet Quality as Assessed by the Healthy Eating Index, Alternate Healthy Eating Index, Dietary Approaches to Stop Hypertension Score, and Health Outcomes: An Updated Systematic Review and Meta-Analysis of Cohort Studies", Journal of the Academy of Nutrition and Dietetics, Vol. 118 No. 1, pp. 74-100.e11.

Schwingshackl, L. and Hoffmann, G. (2015), “Adherence to Mediterranean diet and risk 598 of cancer: an updated systematic review and meta-analysis of observational studies.”, Cancer Medicine, Vol. 4 No. 12, pp. 1933-1947.

Serra-Majem, L., Ortiz-Andrellucchi, A. and Sánchez-Villegas, A. (2019), 601 "Mediterranean Diet", in Ferranti, P., Berry, E.M. and Anderson, J.R. (Eds.), Encyclopedia of Food Security and Sustainability, Elsevier, Oxford, pp. 292-301.

Siegrist, M., Shi, J., Giusto, A. and Hartmann, C. (2015), "Worlds apart. Consumer 604 acceptance of functional foods and beverages in Germany and China", Appetite, 605 Vol. 92, pp. 87-93.

606

Singh, H. (2016), "Nanotechnology Applications in Functional Foods; Opportunities and 607 Challenges", Preventive Nutrition and Food Science, Vol. 21 No. 1, pp. 1-8.

608 Sommer, I., Mackenzie, H., Venter, C. and Dean, T. (2012), "Factors influencing food 609 choices of food-allergic consumers: findings from focus groups”, Allergy, Vol. 67 610 No. 10, pp. 1319-1322. 
611 Stasi, A., Songa, G., Mauri, M., Ciceri, A., Diotallevi, F., Nardone, G. and Russo, V. 612 (2018), "Neuromarketing empirical approaches and food choice: A systematic review", Food Research International, Vol. 108, pp. 650-664.

614 Thodis, A., Itsiopoulos, C., Kouris-Blazos, A., Brazionis, L., Tyrovolas, S., 615 Polychronopoulos, E. and Panagiotakos, D.B. (2018), “Observational study of 616 adherence to a traditional Mediterranean diet, sociocultural characteristics and 617 cardiovascular disease risk factors of older Greek Australians from 618 MEDiterranean ISlands (MEDIS-Australia Study): Protocol and rationale", $619 \quad$ Nutrition \& Dietetics, Vol. 75 No. 1, pp. 44-51.

620 Trichopoulou, A., Costacou, T., Bamia, C. and Trichopoulos, D. (2003), “Adherence to 621 a Mediterranean diet and survival in a Greek population", The New England 622 Journal of Medicine, Vol. 348 No. 26, pp. 2599-2608.

623 World health Organization. (2006), "Global Database on Body Mass Index", available at: 624 http://apps.who.int/bmi/index.jsp?introPage=intro_3.html (accessed 26 July 625 2017).

626 World Health Organization. (2018a), "Healthy diet", World Health Organization, available at: http://www.who.int/news-room/fact-sheets/detail/healthy-diet (accessed 29 October 2018).

629 World Health Organization. (2018b), "Physical activity", World Health Organization, 630 available at: http://www.who.int/news-room/fact-sheets/detail/physical-activity (accessed 7 November 2018). 
632 Yu, E., Malik, V.S. and Hu, F.B. (2018), "Reprint of: Cardiovascular Disease Prevention

633 by Diet Modification: JACC Health Promotion Series", Journal of the American

634 College of Cardiology, Vol. 72 No. 23, Part B, pp. 2951-2963.

635

636 